University of Nebraska - Lincoln

DigitalCommons@University of Nebraska - Lincoln

Faculty Publications - Chemistry Department Published Research - Department of Chemistry

2008

\title{
Local Structures Surrounding Zr in Nanostructurally Stabilized Cubic Zirconia: Structural Origin of Phase Stability
}

\author{
Y. L. Soo \\ National Tsing Hua University, Hsinchu 30013, Taiwan \\ P. J. Chen \\ National Tsing Hua University, Hsinchu 30013, Taiwan \\ S. H. Huang \\ National Tsing Hua University, Hsinchu 30013, Taiwan \\ T. J. Shiu \\ National Tsing Hua University, Hsinchu 30013, Taiwan \\ T. Y. Tsai \\ National Tsing Hua University, Hsinchu 30013, Taiwan \\ See next page for additional authors
}

Follow this and additional works at: https://digitalcommons.unl.edu/chemfacpub

Part of the Chemistry Commons

Soo, Y. L.; Chen, P. J.; Huang, S. H.; Shiu, T. J.; Tsai, T. Y.; Chow, Y. H.; Lin, Y. C.; Weng, S. C.; Chang, S. L.; Wang, G.; Cheung, Chin Li; Sabirianov, Renat F.; Mei, Wai-Ning; Namavar, F.; Haider, H.; Garvin, K. L.; Lee, J. F.; Lee, H. Y.; and Chu, P. P., "Local Structures Surrounding Zr in Nanostructurally Stabilized Cubic Zirconia: Structural Origin of Phase Stability" (2008). Faculty Publications -- Chemistry Department. 18.

https://digitalcommons.unl.edu/chemfacpub/18

This Article is brought to you for free and open access by the Published Research - Department of Chemistry at DigitalCommons@University of Nebraska - Lincoln. It has been accepted for inclusion in Faculty Publications -Chemistry Department by an authorized administrator of DigitalCommons@University of Nebraska - Lincoln. 


\section{Authors}

Y. L. Soo, P. J. Chen, S. H. Huang, T. J. Shiu, T. Y. Tsai, Y. H. Chow, Y. C. Lin, S. C. Weng, S. L. Chang, G.

Wang, Chin Li Cheung, Renat F. Sabirianov, Wai-Ning Mei, F. Namavar, H. Haider, K. L. Garvin, J. F. Lee, H. Y. Lee, and P. P. Chu 


\title{
Local structures surrounding Zr in nanostructurally stabilized cubic zirconia: Structural origin of phase stability
}

\author{
Y. L. Soo, ${ }^{1, a)}$ P. J. Chen, ${ }^{1}$ S. H. Huang, ${ }^{1}$ T. J. Shiu, ${ }^{1}$ T. Y. Tsai, ${ }^{1}{ }^{1}$ Y. H. Chow, ${ }^{1}$ Y. C. Lin, ${ }^{1}$ \\ S. C. Weng, ${ }^{1}$ S. L. Chang, ${ }^{1}$ G. Wang, ${ }^{2}$ C. L. Cheung, ${ }^{2}$ R. F. Sabirianov, ${ }^{3}$ W. N. Mei, ${ }^{3}$ \\ F. Namavar, ${ }^{4}$ H. Haider, ${ }^{4}$ K. L. Garvin, ${ }^{4}$ J. F. Lee, ${ }^{5}$ H. Y. Lee, ${ }^{6}$ and P. P. Chu ${ }^{6}$ \\ ${ }^{1}$ Department of Physics, National Tsing Hua University, Hsinchu 30013, Taiwan \\ ${ }^{2}$ Department of Chemistry, University of Nebraska-Lincoln, Lincoln, Nebraska 68588, USA \\ ${ }^{3}$ Department of Physics, University of Nebraska at Omaha, Omaha, Nebraska 68182, USA \\ ${ }^{4}$ Department of Orthopaedics Surgery and Rehabilitation, University of Nebraska Medical Center, Omaha, \\ Nebraska 68198, USA \\ ${ }^{5}$ National Synchrotron Radiation Research Center, Hsinchu 30013, Taiwan \\ ${ }^{6}$ Department of Chemistry, National Central University, Jhongli 32001, Taiwan
}

(Received 30 September 2008; accepted 28 October 2008; published online 15 December 2008)

\begin{abstract}
Local environment surrounding $\mathrm{Zr}$ atoms in the thin films of nanocrystalline zirconia $\left(\mathrm{ZrO}_{2}\right)$ has been investigated by using the extended x-ray absorption fine structure (EXAFS) technique. These films prepared by the ion beam assisted deposition exhibit long-range structural order of cubic phase and high hardness at room temperature without chemical stabilizers. The local structure around $\mathrm{Zr}$ probed by EXAFS indicates a cubic $\mathrm{Zr}$ sublattice with $\mathrm{O}$ atoms located on the nearest tetragonal sites with respect to the $\mathrm{Zr}$ central atoms, as well as highly disordered locations. Similar $\mathrm{Zr}$ local structure was also found in a $\mathrm{ZrO}_{2}$ nanocrystal sample prepared by a sol-gel method. Variations in local structures due to thermal annealing were observed and analyzed. Most importantly, our x-ray results provide direct experimental evidence for the existence of oxygen vacancies arising from local disorder and distortion of the oxygen sublattice in nanocrystalline $\mathrm{ZrO}_{2}$. These oxygen vacancies are regarded as the essential stabilizing factor for the nanostructurally stabilized cubic zirconia. (c) 2008 American Institute of Physics. [DOI: 10.1063/1.3041490]
\end{abstract}

\section{INTRODUCTION}

The zirconia $\left(\mathrm{ZrO}_{2}\right)$ system has several structural polymorphs such as the cubic, tetragonal, monoclinic, and orthorhombic phases, in which the cubic phase is of most interest in wear-reduction applications due to its high hardness. ${ }^{1}$ Without addition of large amount (up to 20\%) of trivalent stabilizer oxides such as yttria or ceria, pure zirconia is not normally stable in the cubic phase (diamond simulant) at room temperature. ${ }^{2}$ Incorporating these stabilizers in the $\mathrm{ZrO}_{2}$ sample can generate $\mathrm{O}$ vacancies around $\mathrm{Zr}$ and therefore stabilize the cubic structure of bulk zirconia. ${ }^{3}$ However, the mechanical properties of zirconia deteriorate with increasing concentrations of trivalent stabilizing oxides above $8 \%$. ${ }^{4}$ In contrast to bulk $\mathrm{ZrO}_{2}$, formation of cubic phase without chemical stabilizers has been reported in nanocrystalline zirconia powders with an average grain size of $15 \mathrm{~nm} .{ }^{5-7}$ In order to prepare adherent hard protective coating for loadbearing applications, nanostructurally stabilized transparent pure (without chemical stabilizer) cubic zirconia films have also been fabricated by using the ion beam assisted deposition (IBAD) technique. ${ }^{8,9}$ The IBAD method combines physical vapor deposition with concurrent ion beam bombardment in an ultrahigh vacuum environment to produce films with superior properties that are then "stitched" to substrates such as $\mathrm{Si}$, glass, and metallic medical devices. The measured hardness with nanoindentation ${ }^{10,11}$ of nanostructurally stabilized $\mathrm{ZrO}_{2}$ was up to $16 \mathrm{GPa}$ (Ref. 8) (depending on

\footnotetext{
${ }^{a)}$ Electronic mail: soo@phys.nthu.edu.tw.
}

deposition conditions), which is significantly larger than a few gigapascals measured for commercially available $21 \%$ yttria-stabilized single crystal of cubic zirconia. Furthermore, the as-deposited IBAD samples have demonstrated water contact angles of about $0^{\circ}-10^{\circ}$ as compared to those of $50.5^{\circ} \pm 2.3^{\circ}$ for cubic zirconia stabilized by a chemical additive. ${ }^{9}$ In light of these superior properties, the IBADdeposited nanocrystalline $\mathrm{ZrO}_{2}$ films are of great potential in biomedical and other wear-reduction applications and therefore deserve detailed studies.

In order to fully understand the mechanism leading to the stable cubic structure and other physical properties in these nanostructurally stabilized zirconia in the absence of chemical stabilizers, the local structural information pertaining to the bond length variation and structural imperfections is an important prerequisite. To this end, the short-rangeorder extended x-ray absorption fine structure (EXAFS) technique is a uniquely suitable method. In this paper, we present the EXAFS results on IBAD-fabricated films of nanocrystal $\mathrm{ZrO}_{2}$, which includes the as-deposited and those annealed at temperatures of 850 and $1000{ }^{\circ} \mathrm{C}$. A nanocrystalline powder sample of $\mathrm{ZrO}_{2}$ prepared by a sol-gel method without hydrolysis is also measured for comparison. Compared with the standard sol-gel process involving hydrolysis, condensation, and polymerization usually adopted for preparing nanocrystal powders of $\mathrm{ZrO}_{2}$, a process without hydrolysis described in this paper has been found to produce smaller nanoparticles with sizes closer to those in the IBAD samples, and therefore was used in this work. 


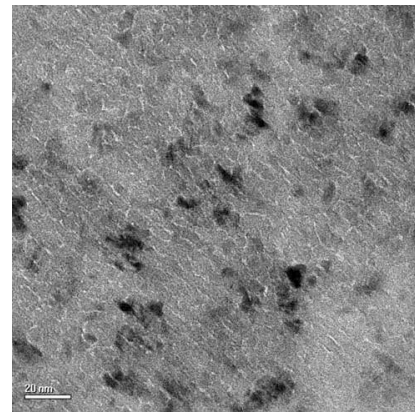

(a)

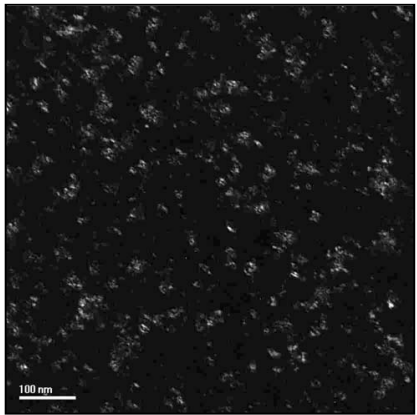

(b)
FIG. 1. (a) Bright field and (b) dark field TEM micrographs of the asdeposited IBAD sample. The size range of the crystallites is $5-8 \mathrm{~nm}$.

\section{EXPERIMENT}

The transparent nanocrystalline $\mathrm{ZrO}_{2}$ samples reported here were prepared by IBAD at the Nanotechnology Laboratory of the University of Nebraska Medical Center. The IBAD system (Mill Lane Engineering, Lowell, MA) is composed of a Veeco $12 \mathrm{~cm}$ rf ion gun that supplies ions at energies up to $1500 \mathrm{eV}$ with a total current density of 500 $\mathrm{mA}$, which provides a broad uniform ion beam of oxygen, nitrogen, and argon and a programable sweep multipocket for electron beam evaporation source. Source material was 99.7\% pure white color $\mathrm{ZrO}_{2}$ with a monoclinic crystal structure from Alfa Aesar (Lot No. C01P41) and was deposited onto silicon, glass, quartz, and metallic substrates. A mixture of $\mathrm{O}$ and $\mathrm{Ar}$ or $\mathrm{N}$ and $\mathrm{Ar}$ ion species of ion energy $500 \mathrm{eV}$ was used with evaporation rate around $3 \AA / s$. Rutherford backscattering spectroscopy (RBS) with $2.275 \mathrm{MeV} \mathrm{He}^{++}$ beam was applied to analyze the chemical composition of zirconia films. Electron beam evaporation powder zirconia with concurrent ion beam bombardment and backfill oxygen at room temperature typically resulted in formation of transparent stoichiometric $\mathrm{ZrO}_{2}$ within accuracy of RBS (4\% for oxygen, Evans Analytical Group Sunnyvale, CA). The surface morphology and crystal structure of the $\mathrm{ZrO}_{2}$ films were characterized by atomic force microscopy, interferometry, $\mathrm{X}$-ray diffractometry (XRD), and transmission electron microscopy (TEM). ${ }^{8,9}$

The as-grown $\mathrm{ZrO}_{2}$ films deposited on silicon substrates at room temperature and pieces of same $\mathrm{ZO}_{2}$ samples annealed at 850 and $1000{ }^{\circ} \mathrm{C}$ were studied by EXAFS. The grain size distribution of nanocrystals was estimated using TEM micrograph to be about $5-8 \mathrm{~nm}$ in diameter (Fig. 1). As shown in Fig. 2, the $\mathrm{x}$-ray diffraction data exhibit cubic phase for the as-deposited and $850{ }^{\circ} \mathrm{C}$-annealed samples. It should be noted that most of the Bragg peaks from the cubic and the tetragonal phases of nanocrystalline $\mathrm{ZrO}_{2}$ are superimposed partly because of the spreading of peaks due to nanostructures. However, if the tetragonal phase exists in the sample, the (112) peak of tetragonal $\mathrm{ZrO}_{2}$ at around $43^{\circ}$, as well as splitting of the (400) line of the fluoritelike $\mathrm{ZrO}_{2}$ structure into (004) and (400) lines with more than one degree of separation, should be observed in the XRD data. ${ }^{12}$ As we can see from Fig. 2, none of these important evidences for tetragonal zirconia were observed in samples studied by EXAFS here. By contrast, they were present in the control

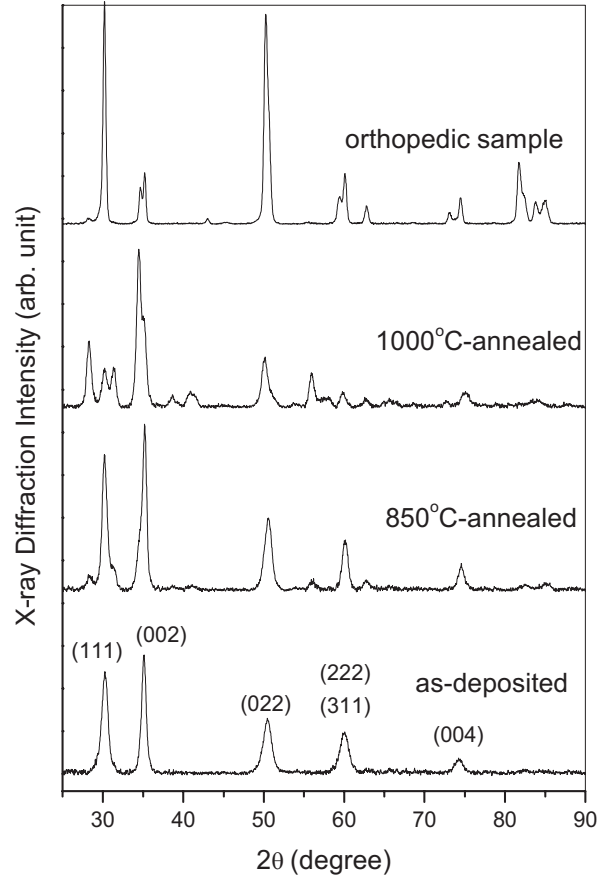

FIG. 2. X-ray diffraction for $\mathrm{ZrO}_{2}$ samples (from top: orthopedic tetragonal knee $\mathrm{ZrO}_{2}, 1000{ }^{\circ} \mathrm{C}$-annealed IBAD $\mathrm{ZrO}_{2}, 850{ }^{\circ} \mathrm{C}$-annealed IBAD $\mathrm{ZrO}_{2}$, and as-deposited IBAD $\mathrm{ZrO}_{2}$ ). Curves have been shifted vertically for clarity.

orthopedics knee sample, which is composed of chemically stabilized tetragonal $\mathrm{ZrO}_{2}$. The possibility of appreciable percentage of tetragonal phase existing in the samples used in this work is therefore excluded. In addition to the cubic peaks, the monoclinic peaks also show up in the XRD of the $1000{ }^{\circ} \mathrm{C}$-annealed sample.

A sol-gel method without hydrolysis was used to prepare a nanocrystal $\mathrm{ZrO}_{2}$ powder sample for EXAFS measurements. In the sol-gel process, zirconium isopropoxide propanol complex $\left(\mathrm{Zr} \cdot\left[\mathrm{OCH}\left(\mathrm{CH}_{3}\right)_{2}\right]_{4} \cdot\left(\mathrm{CH}_{3}\right)_{2} \mathrm{CHOH}\right)$ was used to react with zirconium chloride $\left(\mathrm{ZrCl}_{4}\right)$ in the presence of trioctylphosphine oxide (TOPO) at an elevated temperature of $340{ }^{\circ} \mathrm{C}$. Zirconium oxide powders were then extracted by a series of washing with acetone and water. The particle size of the sol-gel sample was estimated by XRD data using Scherrer equation to be around $3.6 \mathrm{~nm}$ in diameter.

To probe the local structural variation responsible for the enhanced stability in the absence of chemical stabilizer in these nanocrystal samples, the $\mathrm{Zr} K$-edge EXAFS technique was performed on the as-deposited and annealed IBAD samples. The X-ray measurements were carried out in conventional fluorescence mode using an energy dispersive single-element $\mathrm{Si}(\mathrm{Li})$ detector at beamline BL01C at Taiwan Light Source (TLS) of National Synchrotron Radiation Research Center (NSRRC) in Taiwan. For comparison, a nanocrystal powder sample of cubic $\mathrm{ZrO}_{2}$ prepared by a sol-gel method without hydrolysis was also measured.

The EXAFS $\chi$-functions were extracted from the raw experimental data using a well-established data reduction process. ${ }^{13}$ The $\chi$ as a function of photoelectron momentum $(k)$ was truncated and the curve of $\chi$ in between 3.0 and $11.0 \AA^{-1}$ was then Fourier transformed to real (R) space for 
TABLE I. Parameters of the local structure around $\mathrm{Zr}$ atoms obtained from curve fitting of the $\mathrm{Zr} K$-edge EXAFS. $N$ is the coordination number. $R$ is the bond length. $\sigma^{2}$ is the Debye-Waller-type factor that serves as a measure of local disorder. $\Delta E_{0}$ is the difference between the zero kinetic energy value of the sample and that of the theoretical model used in FEFF. Uncertainties were estimated by the double-minimum residue $\left(2 \chi^{2}\right)$ method.

\begin{tabular}{lccccc}
\hline \hline Sample & $\begin{array}{c}\text { Neighboring } \\
\text { atom }\end{array}$ & $N$ & $\begin{array}{c}R \\
(\AA)\end{array}$ & $\begin{array}{c}\sigma^{2} \\
\left(10^{-3} \AA^{2}\right)\end{array}$ & $\begin{array}{c}\Delta E_{0} \\
(\mathrm{eV})\end{array}$ \\
\hline Sol-gel & $\mathrm{O}$ & $3.3 \pm 0.6$ & $2.09 \pm 0.01$ & $6 \pm 2$ & $-8 \pm 5$ \\
& $\mathrm{Zr}$ & $12 \pm 4$ & $3.62 \pm 0.02$ & $10 \pm 2$ & $-3 \pm 4$
\end{tabular}

IBAD

as-deposited

$\begin{array}{ccccc}\mathrm{O} & 4.7 \pm 0.7 & 2.10 \pm 0.01 & 9 \pm 2 & -8 \pm 5 \\ \mathrm{Zr} & 13 \pm 5 & 3.59 \pm 0.02 & 14 \pm 3 & -5 \pm 4\end{array}$

IBAD $850{ }^{\circ} \mathrm{C}-$ annealed

$$
\text { O } \quad 3.2 \pm 0.8 \quad 2.06 \pm 0.01 \quad 5 \pm 2 \quad-12 \pm 5
$$$$
\mathrm{Zr} \quad 14 \pm 5 \quad 3.62 \pm 0.02 \quad 8 \pm 2 \quad-4 \pm 4
$$

IBAD $1000^{\circ} \mathrm{C}-$

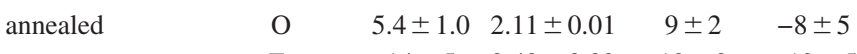

$\mathrm{Zr} \quad 14 \pm 5 \quad 3.43 \pm 0.02 \quad 12 \pm 3 \quad-12 \pm 5$

direct comparison. ${ }^{14}$ To obtain quantitative local structural information, an improved curve-fitting procedure was employed to fit Fourier-filtered functions in $k$-space ${ }^{15,16}$ with theoretical backscattering amplitude and phase-shift functions calculated by the well-known FEFF EXAFS simulation program. ${ }^{17}$ The local structural parameters determined by curve fittings are listed in Tables I. The experimental EXAFS $\chi$-functions and Fourier transforms of the as-deposited and the annealed samples, as well as a nanocrystal powder sample prepared by sol-gel method, are plotted with their respective theoretical curve from curve fittings in Figs. 3 and 4 , respectively.

\section{RESULTS AND DISCUSSION}

As shown in Fig. 3, while the $\chi$-function of the as-grown and the $850{ }^{\circ} \mathrm{C}$-annealed IBAD samples are relatively similar to that of the sol-gel sample, that of the $1000{ }^{\circ} \mathrm{C}$-annealed IBAD sample shows distinctly different features especially in the region above $6.0 \AA^{-1}$ indicating larger local structural variation in this sample. The Fourier transforms shown in Fig. 4 exhibit two pronounced peaks for all four $\mathrm{ZrO}_{2}$ samples. The second peak of the $1000{ }^{\circ} \mathrm{C}$-annealed IBAD sample appreciably shifts to the left in comparison to those of other three samples. The local structural parameters listed in Table I obtained from curvefitting show that the first and the second pronounced peaks represent the nearest $(\mathrm{O})$ shell and the next nearest $(\mathrm{Zr})$ shell from the central $\mathrm{Zr}$ atom, respectively. The simplicity of local structures around $\mathrm{Zr}$ indicates that the crystal structures of the present samples are mostly close to that in the highly symmetric cubic zirconia structure, which has $8 \mathrm{O}$ nearest neighboring atoms at a distance of $2.20 \AA$ followed by $12 \mathrm{Zr}$ next nearest neighboring atoms at $3.59 \AA .{ }^{18}$ However, appreciable deviation from the bulk cubic zirconia structure is observed in these nanocrystal samples. First, the nearest $\mathrm{O}$ shell has a much decreased coordination number of around

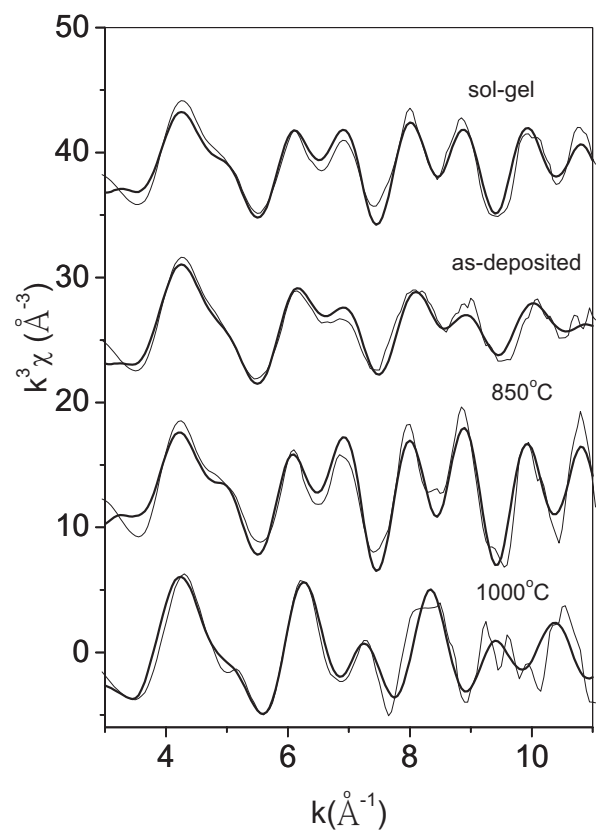

FIG. 3. Weighed $\mathrm{Zr} K$-edge EXAFS $\chi$-functions (from top: sol-gel sample, as-deposited IBAD sample, $850{ }^{\circ} \mathrm{C}$-annealed IBAD sample, and $1000{ }^{\circ} \mathrm{C}$-annealed IBAD sample). Fine lines: experimental; course lines: theoretical. Curves have been shifted vertically for the sake of clarity.

3.2-5.4 in comparison to 8 in the bulk cubic structure. The $\mathrm{Zr}-\mathrm{O}$ bond length of $2.06-2.11 \AA$ in the nanocrystal samples is also substantially shorter than the bulk value of $2.20 \AA$. The decreased number of $\mathrm{O}$ neighboring atoms surrounding $\mathrm{Zr}$ indicates large number of $\mathrm{O}$ vacancies in the nanocrystal $\mathrm{ZrO}_{2}$ samples prepared by either the IBAD or the sol-gel method without hydrolysis. Combined with the effect of shortened bondlength, the presence of $\mathrm{O}$ vacancies

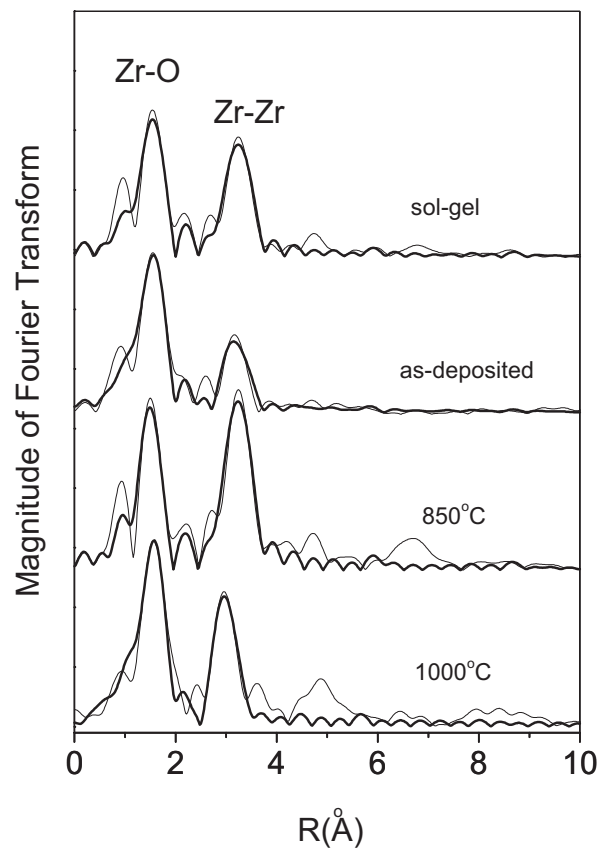

FIG. 4. Fourier transform of $\mathrm{Zr} K$-edge EXAFS $\chi$-functions (from top: solgel sample, as-deposited IBAD sample, $850^{\circ} \mathrm{C}$-annealed IBAD sample, and $1000{ }^{\circ} \mathrm{C}$-annealed IBAD sample). Fine lines: experimental; course lines: theoretical. Curves have been shifted vertically for the sake of clarity. 


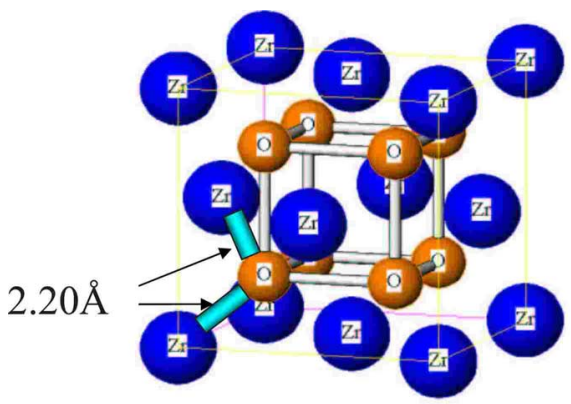

(a)

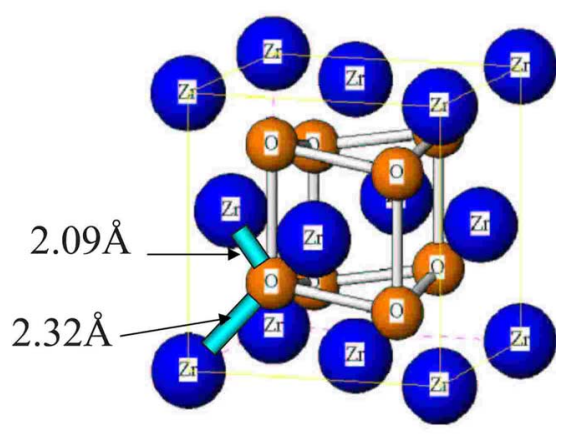

(b)

FIG. 5. (Color online) Arrangement of neighboring atoms surrounding $\mathrm{Zr}$ in (a) cubic and (b) tetragonal zirconia structures.

has thus stabilized the cubic zirconia structure at room temperature in the nanocrystalline $\mathrm{ZrO}_{2}$ samples.

It is worth noting that the decreased first-shell $(\mathrm{O})$ coordination number does not necessarily invalidate the measured stoichiometry of nanocrystalline $\mathrm{ZrO}_{2}$. A large percentage of $\mathrm{O}$ atoms may be relocated at the high energy surface of the nanograin boundaries or at interstitial sites with large local structural disorder and thus were not observed by the short-range-order EXAFS technique. The disorderly relocated $\mathrm{O}$ atoms can therefore leave behind vacancies at the otherwise cubic/tetragonal oxygen sites. Based on our EXAFS data, it seems reasonable to speculate the following structural model (see Fig. 5): a cubic $\mathrm{Zr}$ sublattice with $\mathrm{O}$ atoms sitting on tetragonal-like sites relative to the central $\mathrm{Zr}$ atoms were formed in the sol gel and the as-deposited IBAD samples. Since the grains are small $(3-10 \mathrm{~nm})$ both in the IBAD and sol-gel samples, substantial volume fraction of $\mathrm{ZrO}_{2}$ is on the surface or intergranular regions where the structure could be disordered. Mediated by the random oxygen vacancy distribution, the disorder may propagate predominantly in the oxygen sublattice and thus diminishes long-range tetragonal order; the soft mode displacement in oxygen sublattice is destroyed. As a result, the zirconia exhibit cubic phase structure observed by XRD measurements. At the same time, oxygen locally occupies tetragonal-like positions, which can be seen from the average $\mathrm{Zr}-\mathrm{O}$ interactomic distances.

Moreover, while the next nearest $(\mathrm{Zr})$ shell in three of the four nanocrystal samples has coordination numbers and distances similar to those of the bulk cubic zirconia structure, the $\mathrm{Zr}-\mathrm{Zr}$ distance in the $1000{ }^{\circ} \mathrm{C}$-annealed IBAD sample however dramatically decreases. It is worth noting that the $\mathrm{x}$-ray diffraction has exhibited a mixed cubic and monoclinic long-range-order structures in the $1000{ }^{\circ} \mathrm{C}$-annealed sample in comparison to the pure-cubic structures in the asdeposited and the $850{ }^{\circ} \mathrm{C}$-annealed samples. Our EXAFS analysis demonstrates substantial change in short-rangeorder structure at the same annealing temperature of $1000{ }^{\circ} \mathrm{C}$.

As a side remark, we note that Rush et al. ${ }^{19}$ also reported a much reduced coordination number of 4 for the nearest $\mathrm{O}$ shell from the central $\mathrm{Zr}$ atom in nanocrystalline zirconia. However, the $\mathrm{Zr}-\mathrm{O}$ and $\mathrm{Zr}-\mathrm{Zr}$ distances of 2.13 and $3.41 \AA$, respectively, in their sample is substantially different from our values of 2.06-2.10 $\AA$ and 3.59-3.62 $\AA$ for the three pure-cubic-phase samples, respectively. On the other hand, the values 2.11 and $3.43 \AA$ for our $1000{ }^{\circ} \mathrm{C}$-annealed sample, which has a mixed cubic and monoclinic long-rangeorder structure, are similar to those in their sample. The structures and thermal stability are therefore highly dependent on the different sample preparation methods.

In addition to the most obvious structural differences observed in the $1000{ }^{\circ} \mathrm{C}$-annealed sample, some minor local structural variations are also present among the other three nanocrystal samples. Compared with the sol-gel sample, the as-grown IBAD sample has a larger first-shell coordination number representing less $\mathrm{O}$ vacancies in the sample. However, the local disorder represented by the Debye-Wallertype factor $\left(\sigma^{2}\right)$ in the as-deposited IBAD sample is relatively larger than that in the sol-gel sample for both the first (O) and the second $(\mathrm{Zr})$ shells. Annealing at $850{ }^{\circ} \mathrm{C}$ effectively decreases the overall local disorder as well as the firstshell coordination number and substantially shortens the $\mathrm{Zr}-\mathrm{O}$ bond length in the IBAD sample. When the annealing temperature is increased to $1000{ }^{\circ} \mathrm{C}$, a dramatic local structural variation takes place accompanied by a long-rangeorder phase transition for an appreciable portion of the materials in the IBAD sample.

\section{CONCLUSIONS}

Our EXAFS results have determined the presence of a large amount of $\mathrm{O}$ vacancies in cubic $\mathrm{ZrO}_{2}$ nanocrystal samples prepared by either the IBAD technique or a sol-gel method without hydrolysis. At room temperature, these $\mathrm{O}$ vacancies stabilize the cubic structure of nanocrystal zirconia in the absence of chemical stabilizers in the samples. The cubiclike local structure in the IBAD-grown nanocrystal sample is thermally stable up to an annealing temperature of $850{ }^{\circ} \mathrm{C}$. However, when the annealing temperature is raised to $1000{ }^{\circ} \mathrm{C}$, the local environment around $\mathrm{Zr}$ undergoes a dramatic change, while the long-range-order crystal structure becomes a mixture of cubic and monoclinic phases. More work has to be performed to obtain a full systematic picture regarding the correlation between particle size, local structure, and long-range-order crystal structure in the nanocrystal $\mathrm{ZrO}_{2}$ systems. However, our present work has provided a solid experimental evidence for the existence of a large amount of $\mathrm{O}$ vacancies in nanostructurally stabilized cubic zirconia. Based on the variation in $\mathrm{O}$ coordination number around $\mathrm{Zr}$, our EXAFS results also reveal the dependence of 
$\mathrm{O}$ vacancies on the sample preparation method and annealing temperature which is very useful for vacancy control in fabricating the nanostructurally stabilized cubic zirconia. Without the need to add chemical stabilizers, the nanocrystal $\mathrm{ZrO}_{2}$ possesses favorable physical properties compared to the chemically stabilized bulk cubic zirconia and therefore has great potential for many technological applications.

\section{ACKNOWLEDGMENTS}

The present research has been supported by NSC in Taiwan under Project No. 96-2112-M-007-009. The authors at the University of Nebraska thank the support from the $\mathrm{Ne}$ braska Research Initiative.

${ }^{1}$ P. Li, I. Wei Chen, and J. E. Penner-Hahn, Phys. Rev. B 48, 10063 (1993). ${ }^{2}$ C. Piconi and G. Maccauro, Biomaterials 20, 1 (1999).

${ }^{3} \mathrm{P}$. Li, I. Wei Chen, and J. E. Penner-Hahn, Phys. Rev. B 48, 10074 (1993).

${ }^{4}$ F. F. Lange, J. Mater. Sci. 17, 240 (1982).

${ }^{5}$ M. Lajavardi, D. J. Kenney, and S. H. Lin, J. Chin. Chem. Soc. (Taipei) 47, 1043 (2000).

${ }^{6}$ M. Gateshki, V. Petkov, G. Williams, S. K. Pradhan, and Y. Ren, Phys. Rev. B 71, 224107 (2005).
${ }^{7}$ P. Bouvier, E. Djurado, G. Lucazeau, and T. Le Bihan, Phys. Rev. B 62, 8731 (2000)

${ }^{8}$ F. Namavar, G. Wang, C. L. Cheung, R. F. Sabirianov, X. C. Zeng, W. N. Mei, J. Bai, J. R. Brewer, H. Haider, and K. L. Garvin, Nanotechnology 18, 415702 (2007), and references cited therein.

${ }^{9}$ F. Namavar, C. L. Cheung, R. F. Sabirianov, W. N. Mei, X. C. Zeng, G. Wang, H. Haider, and K. L. Garvin, Nano Lett. 8, 988 (2008).

${ }^{10}$ W. C. Oliver and G. M. J. Phar, Mater. Res. 7, 1564 (1992).

${ }^{11}$ M. F. Doerner and W. D. J. Nix, Mater. Res. 1, 601 (1986).

${ }^{12}$ D. G. Lamas, R. O. Fuentes, I. O. Fabregas, M. E. Fernandez de Rapp, G. E. Lascalea, J. R. Casanova, N. E. Walsoe de Reca, and A. F. Craievich, J. Appl. Crystallogr. 38, 867 (2005).

${ }^{13}$ M. Newville, P. Lïvins, Y. Yacoby, J. J. Rehr, and E. A. Stern, Phys. Rev. B 47, 14126 (1993).

${ }^{14}$ P. A. Lee, P. H. Citrin, P. Eisenberger, and B. M. Kincaid, Rev. Mod. Phys. 53, 769 (1981).

${ }^{15}$ Y. L. Soo, Z. H. Ming, S. W. Huang, Y. H. Kao, R. N. Bhargava, and D. Gallagher, Phys. Rev. B 50, 7602 (1994), and references cited therein.

${ }^{16}$ Y. L. Soo, S. C. Weng, W. H. Sun, S. L. Chang, W. C. Lee, Y. S. Chang, J. Kwo, M. Hong, J. M. Ablett, C.-C. Kao, D. G. Liu, and J. F. Lee, Phys. Rev. B 76, 132404 (2007).

${ }^{17}$ J. J. Rehr, J. Mustre de Leon, S. I. Zabinsky, and R. C. Albers, J. Am. Chem. Soc. 113, 5135 (1991).

${ }^{18}$ R. W. G. Wyckoff, Crystal Structures (Interscience, New York, 1960).

${ }^{19}$ G. E. Rush, A. V. Chadwick, I. Kosacki, and H. U. Anderson, J. Phys. Chem. B 104, 9597 (2000). 